Acta Theriologica 39 (4): 389-397, 1994.

PL ISSN 0001-7051

\title{
Intensity of male reproduction in Brandt's vole Microtus brandti
}

\author{
Zhilong LIU, Zhonglai LI, Laifu LIU and Ruyong SUN
}

Liu Z., Li Z., Liu L. and Sun R. 1994. Intensity of male reproduction in Brandt's vole Microtus brandti. Acta theriol. 39: 389-397.

\begin{abstract}
A new method based on polygonal regression analysis to investigate the relationship between the testis (or seminal vesicle) length and body mass were used to study the dynamics of male reproductive intensity of Brandt's voles Microtus brandti (Radde, 1861). The results showed that the turning (join) points which could be regarded as the minimum body masses commencing sexual development increased from spring to autumn. The slope rates of regression equations which represent the sexual growth rate decreased from spring to autumn. This indicated that the sexual development of males had obvious seasonality similiar to that of the females. By comparing two years, we could find that the slopes in 1987 (population increasing year) were significiantly higher than those of 1988 (population decreasing year). The slopes and the percentage of the voles with body mass larger than the turning point might be reliable indexes of male reproductive intensity for studies of population dynamics in rodents.

Institute of Epidemiology and Microbiology, P. O. Box 5, Changping, Beijing 102206, P. R. China (ZLiu); Department of Mathematics, Beijing Normal University, Beijing 100875, P. R. China (ZL, LL); Department of Biology, Beijing Normal University, Beijing 100875 , P. R. China (RS)

Key words: Microtus brandti, male reproduction, polygonal regression analysis, new method
\end{abstract}

\section{Introduction}

Brandt's vole Microtus brandti (Radde, 1861) is the major pest rodent in the pasture of typical steppe in Inner Mongolia. The population ecology and control of this rodent pest has been intensively studied in the past 40 years, such as physiological age structure, frequency of producing litters, growth rate of cohorts, age at sexual maturation, mean litter size (Anti-epidemic and Health Station 1975, Zhang and Zhong 1979, Liu 1992, Zhou et al. 1992, Liu and Sun 1993a, b). Those results were mostly based on females. Yet very little is known about the male reproduction ecology and the role of males in the population reproduction. Only Zhang and Zhong (1979) studied the monthly changes of percentage of the voles with enlarged seminal vesicles or scrotal testes in the population. We used the polygonal regression to investigate the relationship between sexual organ growth and body mass. Two male reproductive intensity indexes were presented here. 


\section{Material and methods}

The filed site was located at Hongguang Muchang $\left(42^{\circ} 18^{\prime} \mathrm{N}, 115^{\circ} 00^{\prime} \mathrm{E}\right.$, altitude $1346.3 \mathrm{~m}$ a.s.l. $)$, Zhengxiang Baiqi, Xilinggulei League, Inner Mongolia Autonomous Region. This site belongs to the zone of arid steppe with needle grasses and peashrubs. We obtained more than 100 voles per half month by steel snap traps from April to October 1987 and from March to September 1988. The snap traps $(100 \times 45 \mathrm{~mm})$ without any bait were placed on all burrow openings of the sample area at day time. Each trapping period lasted two days in summer or three days in spring and autumn. Captured voles were collected every two hours and carried to a field laboratory to be necropsied directly. The following data were collected: body mass to the nearest $0.5 \mathrm{~g}$, body length to the nearest $0.5 \mathrm{~mm}$, testis and seminal vesicle length to the nearest $0.1 \mathrm{~mm}$, net body mass (body mass without abdominal viscera) to the nearest $0.5 \mathrm{~g}$.

According to the distribution of the net body masses, the voles were classified as overwintered and born in this year (Liu and Sun 1993a). Because too few voles born in this year were captured in late half of May $1988(n=7)$, they were combined to early June (called May-June).

The rodents grow and develop continuously, but at an uneven rate. The sexual organs of young animals are undeveloped, although body mass increases rapidly. After sexual maturation is attained, the sexual organs grow slowly or remain at a relatively constant state. The sexual organs (testis or seminal vesicle) were divided into three groups: "Mature" - largest testis; "Rudimental" - lightest body mass, the testes remained thin and small and increased slowly, relative to the increase in body masses that was rapid; "Growth" - the intermediate group, the testis increased rapidly. Our problem was how to classify these three groups by using a mathematical method, and to determine the turning point between the groups.

The mean length of the testis of overwintered voles could be regarded as the turning point between "Growth" and "Mature" because the overwintered voles were all sexually mature (see Table 1). In the present study, "Mature" (excluding overwintered voles) is neglected because some sample sizes are too small. The numbers of deleted voles whose testes were longer than the mean of overwintered voles were as follows: 0 (late May and early June), 2 (June--July), 8 (July-Aug), 10 (Aug-Sep) in 1987 and 0 (May-June), 2 (June-July), 12 (July-Aug), 2 (Aug-Sep) in 1988.

The linear regression could be used to analyze "Growth" and "Rudimental" states with respect to body mass. But the problem remaining to be solved is how to determine the turning point between two groups. For a data set of size $m\left(\mathrm{X}_{i}, \mathrm{Y}_{i}\right)(i=1,2, \ldots \ldots, m)$ characterized the two random variables $\mathrm{Y}\left(=\right.$ testis or seminal vesicle length) and $\mathrm{X}$ (= body mass), where the data are ordered such as $\mathrm{X}_{1}<$ $\mathrm{X}_{2}<\ldots<\mathrm{X}_{m}$, we could select one turning point $\mathrm{J}$, such that $\mathrm{X}_{1}<\mathrm{J}<\mathrm{X}_{m}$. Let

$$
Y= \begin{cases}A_{1}+K_{1} X & \text { for } X \leq J \\ A_{2}+K_{2} X & \text { for } X>J,\end{cases}
$$

where: $A_{1}+K_{1} T=A_{2}+K_{2} T$. $K_{1}$ and $K_{2}$ stand for the slopes of the linear regressions. The polygonal regression equation with one turning point $J$ could be expressed as:

$$
\mathrm{H}_{(\mathrm{X})}=\mathrm{C}_{0}+\mathrm{C}_{1} \mathrm{X}+\mathrm{C}_{2}(\mathrm{X}-\mathrm{J})_{+}
$$

where: $(X-J)_{+}= \begin{cases}0 & \text { for } X \leq J \\ X-J & \text { for } X>J,\end{cases}$

$\mathrm{C}_{0}, \mathrm{C}_{1}$ and $\mathrm{C}_{2}$ are parameters remaining to be determined. If we let $\mathrm{Z}_{1}=\mathrm{X}, \mathrm{Z}_{2}=(\mathrm{X}-J)_{+}$, then Eq. (2) may be expressed as:

$$
\mathrm{H}_{(\mathrm{X})}=\mathrm{C}_{0}+\mathrm{C}_{1} \mathrm{Z}_{1}+\mathrm{C}_{2} \mathrm{Z}_{2}
$$

So the polygonal regression Eq. (2) could be transformed to multivariate linear regression Eq. (3).

Then turning points were determined by using the method of exhaustion. That is to search for the integral number point $\left(\mathrm{J}_{0}\right)$ such that $\mathrm{X}_{i}<\mathrm{J}_{0}<\mathrm{X}_{m}$, minimizes the residual sum of squares $\Sigma\left(\mathrm{Y}_{i}-\mathrm{C}_{0}\right.$ $\left.-\mathrm{C}_{1} \mathrm{Z}_{i 1}-\mathrm{C}_{2} \mathrm{Z}_{i 2}\right)^{2}$ (or maximize the $F$ value in the significance test). Where $\mathrm{Z}_{i 1}$ and $\mathrm{Z}_{i 2}$ were converted from the original data by the formula $Z_{1}=X, Z_{2}=(X-J)_{+}$. In other words, we regard all the integral 
numbers which are larger than $\mathrm{X}_{i}$ and smaller than $\mathrm{X}_{m}$ as the turning point and calculate multivarite regress equations, the residual sum of squares and $F$ values. By comparing all $F$ values or values of the residual sum of squares, the turning point could be selected.

The turning point could be regarded as the minimum body mass in which sexual organs of the young began to develop rapidly. The slope of regression equation was regarded as the growth rate of sexual organs. So there is a turning point (in biology not in mathematics) only when $\mathrm{K}_{2}>\mathrm{K}_{1}$. If the turning point (biological) is not existing, the linear regression could be used instead of polygonal regression and expressed as

$$
\mathrm{Y}_{3}=\mathrm{A}_{3}+\mathrm{K}_{3} \mathrm{X}
$$

Fang and Sun (1989) investigated the population dynamics of Brandt's voles at the same study site and indicated that population was increasing in 1987 and decreasing in 1988.

\section{Results}

The body masses, testis and seminal vesicle length of overwintered voles and voles born of this year were listed in Table 1 and 2, respectively. All captured overwinterd voles had enlarged seminal vesicles and scrotal testes. From April to July in two years, there were no significant differences between the mean length of testes (seminal vesicles) for overwintered animals (e.g. April to July, testis: in 1987, $t=0.1116, p>0.01$; in 1988, $t=1.9236, p>0.01$ respectively; seminal vesicle: in $1987, t=1.9688, p>0.01$; in $1988, t=1.7934, p>0.01$ ). So we could conclude that the length of sexual organs of overwintered voles changed very little through the breeding season.

The polygonal regression equations reached a significant level $(p<0.001$, Tables 3 and 4). There were significant differences between $K_{1}$ and $K_{2}$ of equations in Tables 3 and $4(p<0.001)$. This indicated that the turning points were existing in those months. But in early June of $1987, \mathrm{~K}_{1}(0.9772)$ were larger than $\mathrm{K}_{2}$ $(0.2877)(\mathrm{J}=10)$ and there was no significant differences between $\mathrm{K}_{1}(0.1105)$ and $\mathrm{K}_{2}(=0.3207)$ in late May $(\mathrm{J}=9)$. So, the (biological) turning points were not

Table 1 . The range of body mass, mean $\pm \mathrm{SE}$ length of testis and seminal vesicle length in overwintered voles Microtus brandti.

\begin{tabular}{llcccc}
\hline Year & Month & $\begin{array}{c}\text { Sample size } \\
(n)\end{array}$ & $\begin{array}{c}\text { Body mass } \\
(\mathrm{g})\end{array}$ & $\begin{array}{c}\text { Mean length } \\
\text { of testis } \\
(\mathrm{mm})\end{array}$ & $\begin{array}{c}\text { Mean length } \\
\text { of seminal vesicle } \\
(\mathrm{mm})\end{array}$ \\
\hline 1987 & April & 26 & $34.5-75.0$ & $14.79 \pm 1.21$ & $16.92 \pm 2.18$ \\
& May & 92 & $35.5-78.0$ & $14.92 \pm 1.37$ & $17.22 \pm 2.52$ \\
& June & 23 & $47.5-67.5$ & $15.33 \pm 1.07$ & $17.72 \pm 2.28$ \\
& July & 19 & $48.0-68.0$ & $14.90 \pm 0.79$ & $18.26 \pm 2.31$ \\
1988 & April & 84 & $29.0-69.0$ & $14.69 \pm 1.38$ & $17.29 \pm 3.79$ \\
& May & 101 & $40.0-71.0$ & $15.04 \pm 1.09$ & $18.03 \pm 2.84$ \\
& June & 46 & $42.0-73.0$ & $15.14 \pm 1.14$ & $18.91 \pm 2.60$ \\
& July & 16 & $49.0-58.0$ & $15.34 \pm 1.21$ & $19.05 \pm 3.56$ \\
\hline
\end{tabular}


existing in late May and early June. The reason was that there were too few voles with body mass smaller than the (mathematics) turning point (late May, $n=3$ ). So, the linear regression equations were present in Table 3 and also the lightest body mass was considered as the turning point. This indicated that all the young appearing on the ground had commenced sexual growth. The turning points increased from spring to autumn significantly (Tables 3 and $4, p<0.001$; mean square successive difference test, Neumann 1941, Seber 1977).

Table 2. The range of body mass, testis length, and seminal vesicle length of Brandt's voles born in this year (excluding "Mature").

\begin{tabular}{llrcc}
\hline Year & Month & $\begin{array}{c}\text { Body mass } \\
(\mathrm{g})\end{array}$ & $\begin{array}{c}\text { Seminal vesicle length } \\
(\mathrm{mm})\end{array}$ & $\begin{array}{c}\text { Testis length } \\
(\mathrm{mm})\end{array}$ \\
\hline \multirow{2}{*}{1987} & Late May & $7.0-25.0$ & $2.0-6.0$ & $3.0-10.5$ \\
& Early June & $8.0-37.0$ & $1.0-10.0$ & $3.5-14.0$ \\
& June-July & $5.0-39.0$ & $1.0-13.5$ & $3.5-10.5$ \\
& July-Aug & $5.5-39.0$ & $1.5-8.5$ & $1.5-9.5$ \\
& Aug-Sep & $11.0-42.0$ & $1.5-7.5$ & $2.5-8.0$ \\
1988 & May-June & $7.0-28.5$ & $1.0-11.0$ & $2.0-11.5$ \\
& June-July & $8.0-42.0$ & $1.0-14.0$ & $2.0-13.5$ \\
& July-Aug & $10.0-39.0$ & $1.5-8.5$ & $1.5-8.5$ \\
& Aug-Sep & $11.0-35.0$ & $2.5-8.0$ & $2.0-6.5$ \\
\hline
\end{tabular}

Table 3. Polygonal regression equations of testis length $(\mathrm{Y})$ and body mass $(\mathrm{X})$ of Brandt's voles ( $\mathrm{Y}_{3}$ present linear regression equation).

\begin{tabular}{|c|c|c|c|c|c|c|c|}
\hline Year & Month & Regression equations & & $n$ & $F$ value & $p$ & $\begin{array}{c}\text { Minimum body } \\
\text { mass at sexual } \\
\text { maturation }\end{array}$ \\
\hline \multirow[t]{5}{*}{1987} & Late May & $\mathrm{Y}_{3}=1.9715+0.3166 \mathrm{X}$ & & 85 & 197.46 & $<0.001$ & 15.88 \\
\hline & Early June & $\mathrm{Y}_{3}=2.3634+0.2964 \mathrm{X}$ & & 78 & 120.46 & $<0.001$ & 15.64 \\
\hline & June-July & $\begin{array}{l}Y=2.5661+0.0720 X \\
Y=-0.8126+0.2189 X\end{array}$ & $\begin{array}{l}X \leq 23 \\
X>23\end{array}$ & 162 & 51.91 & $<0.001$ & 37.40 \\
\hline & July-Aug & $\begin{array}{l}Y=3.6575+0.0327 X \\
Y=-1.8647+0.2231 X\end{array}$ & $\begin{array}{l}X \leq 29 \\
X>29\end{array}$ & 221 & 64.04 & $<0.001$ & 39.73 \\
\hline & Aug-Sep & $\begin{array}{l}Y=3.3536+0.0321 X \\
Y=-0.9027+0.1694 X\end{array}$ & $\begin{array}{l}X \leq 31 \\
X>31\end{array}$ & 250 & 82.07 & $<0.001$ & 46.65 \\
\hline \multirow[t]{4}{*}{1988} & May-June & $\begin{array}{l}\mathrm{Y}=4.1441+0.0972 \mathrm{X} \\
\mathrm{Y}=1.3864+0.3086 \mathrm{X}\end{array}$ & $\begin{array}{l}X \leq 13 \\
X>13\end{array}$ & 45 & 110.96 & & 18.15 \\
\hline & June-July & $\begin{array}{l}Y=2.7005+0.1429 \mathrm{X} \\
\mathrm{Y}=1.0525+0.2253 \mathrm{X}\end{array}$ & $\begin{array}{l}X \leq 20 \\
X>20\end{array}$ & 91 & 28.44 & $<0.001$ & 26.40 \\
\hline & July-Aug & $\begin{array}{l}Y=4.6785+0.0387 X \\
Y=0.4420+0.2152 X\end{array}$ & $\begin{array}{l}X \leq 24 \\
X>24\end{array}$ & 145 & 31.48 & $<0.001$ & 30.47 \\
\hline & Aug-Sep & $\begin{array}{l}\mathrm{Y}=4.7936+0.0403 \mathrm{X} \\
\mathrm{Y}=-1.2441+0.1668 \mathrm{X}\end{array}$ & $\begin{array}{l}\mathrm{X} \leq 28 \\
\mathrm{X}>28\end{array}$ & 137 & 8.02 & $<0.001$ & 49.43 \\
\hline
\end{tabular}


$\mathrm{K}_{1}$ of all the polygonal regression equations was much smaller. Tables 3 and 4 also indicate that $\mathrm{K}_{2}$ had seasonal variations significantly (ANOVA, Table 3: 1987, $F=-111.67, p<0.001 ; 1988, F=-31.10, p<0.001$; Table 4: 1987, $F=$ $-55.47, p<0.001 ; 1988, F=-6.93, p<0.05)$. There were significant differences

Table 4. Polygonal regression equations of seminal vesicle length $(\mathrm{Y})$ and body mass $(\mathrm{X})$ of Brandt's voles.

\begin{tabular}{|c|c|c|c|c|c|c|}
\hline Year & Month & Regression equations & & $n$ & $F$ value & $p$ \\
\hline \multirow[t]{9}{*}{1987} & \multirow[t]{2}{*}{ Late May } & $\mathrm{Y}=1.7313+0.0787 \mathrm{X}$ & $\mathrm{X} \leq 10$ & & & \\
\hline & & $\mathrm{Y}=0.5979+0.1921 \mathrm{X}$ & $X<10$ & 84 & 75.67 & $<0.001$ \\
\hline & \multirow[t]{2}{*}{ Early June } & $\mathrm{Y}=2.1115+0.0922 \mathrm{X}$ & $\mathrm{X} \leq 24$ & & & \\
\hline & & $Y=-5.8522+0.4241 X$ & $X>24$ & 78 & 94.44 & $<0.001$ \\
\hline & June-July & $\begin{array}{l}\mathrm{Y}=2.5914+0.0271 \mathrm{X} \\
\mathrm{Y}=-1.8842+0.1993 \mathrm{X}\end{array}$ & $\begin{array}{l}\mathrm{X} \leq 26 \\
\mathrm{X}>26\end{array}$ & 162 & 37.23 & $<0.001$ \\
\hline & \multirow[t]{2}{*}{ July-Aug } & $\mathrm{Y}=1.5654+0.0503 \mathrm{X}$ & $\mathrm{X} \leq 32$ & & & \\
\hline & & $Y=-2.7194+0.1842 X$ & $\mathrm{X}>32$ & 221 & 113.38 & $<0.001$ \\
\hline & \multirow[t]{2}{*}{ Aug-Sep } & $\mathrm{Y}=1.4367+0.0303 \mathrm{X}$ & $\mathrm{X} \leq 31$ & & & \\
\hline & & $\mathrm{Y}=0.8220+0.1061 \mathrm{X}$ & $\mathrm{X}>31$ & 250 & 15.82 & $<0.001$ \\
\hline \multirow[t]{8}{*}{1988} & \multirow[t]{2}{*}{ May-June } & $\mathrm{Y}=2.3823+0.0725 \mathrm{X}$ & $\mathrm{X} \leq 23$ & & & \\
\hline & & $Y=-2.6581+0.2916 \mathrm{X}$ & $X>23$ & 45 & 8.02 & $<0.01$ \\
\hline & \multirow[t]{2}{*}{ June-July } & $\mathrm{Y}=1.2553+0.0818 \mathrm{X}$ & $\mathrm{X} \leq 32$ & & & \\
\hline & & $Y=-2.7514+0.2070 X$ & $\mathrm{X}>32$ & 91 & 8.66 & $<0.001$ \\
\hline & \multirow[t]{2}{*}{ July-Aug } & $Y=1.9854+0.0795 X$ & $X \leq 27$ & & & \\
\hline & & $\mathrm{Y}=1.6320+0.0926 \mathrm{X}$ & $X>27$ & 145 & 9.94 & $<0.001$ \\
\hline & \multirow[t]{2}{*}{ Aug-Sep } & $\mathrm{Y}=0.1989+0.0020 \mathrm{X}$ & $\mathrm{X} \leq 30$ & & & \\
\hline & & $Y=-0.5377+0.0932 X$ & $\mathrm{X}>30$ & 137 & 2.09 & $<0.02$ \\
\hline
\end{tabular}

Table 5. The percentage of Brandt's voles with body mass larger than the turning points (A) and with testis longer than $7 \mathrm{~mm}(\mathrm{~B})$ in the population.

\begin{tabular}{|c|c|c|c|c|c|c|c|c|}
\hline \multirow{3}{*}{ Month } & \multicolumn{4}{|c|}{1987} & \multicolumn{4}{|c|}{1988} \\
\hline & \multicolumn{2}{|c|}{ A } & \multicolumn{2}{|c|}{ B } & \multicolumn{2}{|r|}{ A } & \multicolumn{2}{|r|}{ B } \\
\hline & $\begin{array}{c}\% \text { of all } \\
\text { voles }\end{array}$ & $\begin{array}{c}\% \text { of voles } \\
\text { born in } \\
\text { this yr }\end{array}$ & $\begin{array}{c}\% \text { of all } \\
\text { voles }\end{array}$ & $\begin{array}{c}\% \text { of voles } \\
\text { born in } \\
\text { this yr }\end{array}$ & $\begin{array}{c}\% \text { of all } \\
\text { voles }\end{array}$ & $\begin{array}{c}\% \text { of voles } \\
\text { born in } \\
\text { this yr }\end{array}$ & $\begin{array}{c}\% \text { of all } \\
\text { voles }\end{array}$ & $\begin{array}{c}\% \text { of voles } \\
\text { born in } \\
\text { this yr }\end{array}$ \\
\hline Late May & 81.1 & 97.6 & 19.0 & 22.4 & & & & \\
\hline Early June & 76.8 & 97.4 & 62.6 & 79.5 & 25.8 & 66.7 & 20.7 & 53.3 \\
\hline June-July & 55.2 & 61.6 & 26.2 & 29.3 & 34.5 & 44.1 & 30.3 & 38.7 \\
\hline July-Aug & 28.5 & 28.8 & 7.8 & 7.9 & 20.6 & 21.0 & 18.8 & 19.1 \\
\hline Aug-Sep & 33.9 & 33.9 & 8.4 & 8.4 & 15.3 & 15.3 & 13.1 & 13.1 \\
\hline
\end{tabular}


in the slopes $\left(\mathrm{K}_{2}\right)$ between 1987 and 1988 (ANOVA, Table 3; $p<0.001$; Table 4; $p<0.001$ ). The sexual organs of voles in 1987 grew and matured fast and early. This trend also has been shown by the females (Liu and Sun 1993b).

Males were considered to be sexually mature (could produce mature sperms) if their testes were longer than $7 \mathrm{~mm}$ (Zhang and Zhong 1979, Zhang 1989). Then using this value $\left(\mathrm{Y}_{2}\right.$ or $\left.\mathrm{Y}_{3}=7\right)$ to solve the equations, we could obtain the minimum body masses of male voles at sexual maturation (Table 3 ). The percentage of the voles with body mass larger than the turning point and that of the voles with testis longer than $7 \mathrm{~mm}$ also could be calculated (Table 5). The minimum body mass of male voles at sexual maturation and the percentages of Brandt's voles with body mass larger than the turning points and with testes longer than $7 \mathrm{~mm}$ in the population varies seasonally (Table 5). In females, the pregnancy rates also show the obvious seasonality (Table 5) (Liu and Sun 1993b). Liu and Sun (1993b) also indicated that the voles began breeding earlier in 1987 and the pregnancy rates of 1987 were relatively higher than those of 1988. The percentages of reproductive males also showed the same trend. Hence, reproductive activity of the two sexes is consistent.

\section{Discussion}

In studies of rodent ecology, the reproductive conditions of females has been emphasised and widely investigated. The reproductive intensity of male rodents has been rather neglected or overlooked (Sun et al. 1977, Keller 1985). The main reasons might be that there are no reliable and quantitative indexes of male rodents reproductive activity. On the other hand, the female reproductive profermance is probably most important demographically. This had brought some authors' attentions (Kalera 1957, Sun et al. 1977, Xia et al. 1982, Zhang 1986, 1987, 1989).

The monthly variations of mean weight (length) of testes or seminal vesicle were used as indicators of the male reproduction in many studies (Zhang 1987, Kenagy and Barnes 1988, Hilton 1992, Mills et al. 1992, Wang et al. 1992, Zhou et al. 1992). Although seminal vesicles of adults could wither to varying degrees in the non-breeding season, the length of testis (or seminal vesicle) changes very little during the breeding season (Sun et al. 1977, see also Table 1). Some published papers had also used the percentage of the rodents with enlarged seminal vesicles or scortal testes in the population to represent male breeding intensity (Zhang and Zhong 1979, Beacham 1980, Xia et al. 1982, Mills et al. 1992, Wang et al. 1992, Zhou et al. 1992). As long as we accept scortal testes or enlarged seminal vesicles as the standards for grouping non-reproductive and reproductive rodents, variation of these two percentages only indicate the changes of the population structure. 
The scattered plots of the testes weight against body mass without viscera had been applied to show the tendency of the male breeding intensity (e.g. Zhang 1987, 1989), but the data were not analyzed statistically. Zhang (1986) used linear regression to investigate the relationship between testis weight and body mass without viscera in striped hamsters, but he did not turn sufficient attention to the scarcity of his data. His result could not show the pattern of male reproduction as revealed in the present paper.

Another approach was taken by Sun et al. (1977) who grouped Clethrionomys rufocanus and Apodemus sp. samples into weight classes of $3 \mathrm{~g}$ and divided the testis (seminal vesicle) into three groups. Then the intermediate group was analyzed by using the linear regression whereas the other two groups were not analyzed. But this determination of turning points was done objectively, hence the turning point was not trustworthy.

Liu and Sun (1993a, b) indicated that Brandt's vole had a short lifespan (about one year) and the population had very high turnover rates. Before the latter half of May, the population was composed only of overwintereds. As soon as the voles born in this year entered the population, they replaced the overwintereds rapidly. Four cohorts were produced from the latter half of April to the first half of September. The voles born in spring grew and matured very rapidly and reached sexual maturation to begin breeding at 3 or 4 weeks of age. These early maturing animals had almost disappeared from the population in autumn. Whereas the young born in the middle or late summer and autumn grew slowly and did not reach sexual maturity in fall and resumed growth again the following spring. These overwintereds (having more than 30 weeks of age) constitute the breeding population in early April.

Our results also indicated that the growth and sexual development of males have an obvious seasonality similar to that of the females. This seasonality could be indicated by three aspects. The first was the turning points. In spring the voles with a body mass of $9 \mathrm{~g}$ initiated sexual development and in autumn the voles only with body mass larger than $31 \mathrm{~g}$ could begin sexual growth (Table 3 ). The second was the growth rate of sexual organs $\left(\mathrm{K}_{2}\right)$. The growth rate could reach 0.32 in spring and in contrast only 0.17 in fall (Table 3 ). The third was the minimum body mass at sexual maturation. In late May of 1987, the voles with a body mass of $15.9 \mathrm{~g}$ were able to produce mature sperm. But in July-August of 1987, this minimum body mass reached $39.7 \mathrm{~g}$ (Table 3 ).

This seasonality also indicated that the vole's physiological age differed from the chronological age. As the voles having the same body mass in different seasons may belong to different age group. So one should be most cautious to use the chronological age standards such as body mass, body length, net body mass, morphology of skull and tooth to categorize the Brandt's voles into four groups such as juvenile, subadult, adult one and two. Zhang and Zhong (1979) indicated that $35 \%$ of the juvenile group in May, 1975 were pregnant. This shows that it is necessary to determine the physiological age group instead of the chronological 
age group or at least to use different body mass (length) standards in different seasons (Liu and Sun 1993a).

In conclusion, male voles have the same seasonal reproduction pattern as the females. Our analysis also has demonstrated that the growth rates of male sexual organs and the percentage of voles with testes longer than $7 \mathrm{~mm}$ or body masses larger than a given turning point could be used as indexes of male reproductive intensity.

Acknowledgements: This study was a part of the Seventh Five-year-plan key work of the National Plan Committee (75-03-02-04) and supported by the National Plan Committe and the Ministry of Agriculture. We also thank Mr B. Liang, P. Yuan, J. Xue and M. Xue for their field work and Dr X. Lai and Miss T. Marcolongo for correcting the English.

\section{References}

Anti-epidemic and Health Station of Silingulei Meng of the Inner Mongolia Autonomous Region. 1975. An ecological study of Brandt's Voles (Microtus brandti). Acta zool. Sinica 21: 30-39. [In Chinese with English summary]

Beacham T. D. 1980. Breeding characteristics of Townsend's vole (Microtus townsendii) during population fluctuation. Can. J. Zool. 58: 623-625.

Fang J. and Sun R. 1989. Seasonal changes of Brandt's voles and their relation to burrows. Acta theriol. Sinica 9: 202-209. [In Chinese with English summary]

Hilton B. L. 1992. Reproduction in Mexican vole, Microtus mexicanus. J. Mammal. 73: 580-590.

Kalera O. 1957. Regulation of reproduction rate in subarctic population of vole, Clethrionomys rufocanus. Ann. Acad. Sci. Fenn. Ser. A. Biol. 34: 65-71.

Keller B. L. 1985. Reproductive pattern. [In: Biology of New World Microtus. R. H. Tamarin, ed]. Spec. Publ. Amer. Soc. Mamm. 8: 725-778.

Kenagy G. J. and Barnes B. M. 1988. Seasonal reproduction patterns in four coexisting rodent species from the Cascade Montains, Washington. J. Mammal. 69: 274-292.

Liu Z. 1992. Study on tendency prediction of population fluctuation of Brandt's voles. Chinese J. Vector Biol. and Control 3: 299-304. [In Chinese with English summary]

Liu Z. and Sun R. 1993a. Study on physiological age structure of Brandt's voles (Microtus brandti). Acta theriol. Sinica 13: 50-60. [In Chinese with English summary]

Liu Z. and Sun R. 1993b. Study on population reproduction dynamics of Brandt's voles, Microtus brandti. Acta theriol. Sinica 13: 114-122. [In Chinese with English summary]

Mills J. N., Ellis B. A., Mckee K. T., Maiztegui J. I. and Childs J. E. 1992. Reproductive characteristics of rodent assemblances in cultivated regions of central Argentine. J. Mammal. 73: 515-526.

Neumann J. von, Kent R. H., Bellinson B. H. and Hart B. I. 1941. The mean square successive difference. Ann. Math. Statist. 12: 153-162.

Seber G. A. F. 1977. Linear regression analysis. John Wiley \& Sons, New York: 1-465.

Sun R., Zhang Y. and Fang X. 1977. On the role of male reproductive intensity in the ecological studies of the rodent reproduction. Acta zool. Sinica 23: 187-200. [In Chinese with English summary]

Wang T., Liu J. and Shao M. 1992. Studies on the population reproduction characteristics of Daurian ground squirrel (Spermophilus dauricus). Acta theriol. Sinica 12: 147-152. [In Chinese with English summary]

Xia W., Liao C., Zhong W., Sun C. and Tian Y. 1982. On the population dynamics and regulation of Meriones unguiculatus in agricultural region North to Yin Montains, Inner Mongolia. Acta theriol. Sinica 2: 51-71. [In Chinese with English summary] 
Zhang J. 1986. Studies on population reproduction ecology of striped hamsters in Daxing country, Beijing. Acta theriol. Sinica 6: 45-56. [In Chinese with English summary]

Zhang J. 1987. Studies on population breeding ecology of greater long-tailed hamster in Beijing Area. Acta theriol. Sinica 7: 224-232. [In Chinese with English summary]

Zhang J. 1989. On population age and reproduction of Apodemus agrarius in Beijing Area. Acta theriol. Sinica 9: 41-48. [In Chinese with English summary]

Zhang J. and Zhong W. 1979. Investigations of reproduction in populations of Brandt's voles. Acta zool. Sinica 25: 250-259. [In Chinese with English summary]

Zhou Q., Zhong W. and Wang G. 1992. Density factor in the regulation of Brandt's voles population. Acta theriol. Sinica 12: 49-56. [In Chinese with English summary]

Received 23 August 1993, revised 17 May 1994, accepted 4 August 1994. 